\title{
A Study Of The Relationship Between Occupational Stress And Emotional Intelligence Of Degree College Teachers
}

\author{
Dr. Prashantha Kumara T M
}

Assistant Professor, Department of Studies in Education, Vijayanagara Sri Krishnadevaraya University, Jnanasagara Campus Ballari-583105

prashantkumar.hpt@gmail.com

Article History: Received: 10 November 2020; Revised 12 January 2021 Accepted: 27 January 2021; Published online: 5 April 2021

\begin{abstract}
In this study we examined the relationship between occupational stress and emotional intelligence among Degree College Teachers. We also explored the role of socio-demographic factors on occupational stress and emotional intelligence. Samples comprised of 200 college teachers, Karnataka, India (110 males and 90 females) between the age group of 28 to 60 years (mean age $=46.7$ years) randomly selected from Degree College Teachers affiliated by V.S.K. University. Bellary, India. Tools used for data collection were the (1) Emotional Intelligence Scale (Hyde, Pethe, and Dhar, 2002), (2) Occupational Stress Index (Srivastava and Singh, 1981) and (3) the Personal Information Schedule.Chosen after a comprehensive review of related literature. The samples were contacted individually by the researcher and data was collected through face to face interview. Data collection was spread over a period of one month. Mean, SD, ' $t$ ' test, and Pearson product moment correlation were the statistical analyses done. From the result we found that emotional intelligence and occupational stress were negatively and significantly related. We also found that socio-demographic variables such as, gender educational qualification, residential status, income and family type were not significant on influence both occupational stress and emotional intelligence. However age had a significant influence on occupational stress and emotional intelligence. However, age had a significant influence on emotional intelligence but was not significant for occupational stress.
\end{abstract}

Keywords: Emotions, Emotional intelligence, Occupational Stress, Socio-Demographic factors.

\section{Introduction}

Emotion is fundamental and indivisible element in the context of work life. Since the appraisal of emotions is intricate they have mostly been neglected in organizational literature. Emergency of the nation of intelligence (EI) offers a fresh outlook into the study of emotions. In which emotions have transformed from being primarily considered distracting elements of cognitive process to being perceived as essential experience of human being offering constructive information on every day problem solving. From this perspective the intelligence use of emotion is considered crucial for one 's psychological adaptation (Mayer and Salovey, 1990) in recent years the concept of emotional intelligence (EI) has engrossed enormous extent of inquisitiveness from academicians, researchers and mental health practitioners. Now -a-days EI has becomes the product of both popular and scientific literature. Though EI comparatively a novel and potential area of psychological research, it has grasped the attention encompasses.

The term emotional intelligence was pioneered in 1985 by Wayne Payne inhis doctoral thesis and in 1987 Keith Beasley used the term emotional quotient in an article published in 'Mensa Magazine'.In the year 1990 psychologists Peter Salovey and John Mayer published their landmark article, "Emotional Intelligence" in the journal'Imagination, Cognition and Personality', and since then had continued to be the foremost investigators in this area. However the idea of EI got popularized in 1995 following the in print of Daniel Goleman's (Psychologist and New York Times Science Writer) book "Emotional Intelligence:Why it Can Matter More than IQ." Daniel Goleman also developed a framework of five elements that define EI, namely, self -awareness, self regulation, motivation, empathy and social skills.

\section{2. $\quad$ Need of the Study}

Emotional intelligence though relatively a new concept has its roots in the notion of social intelligence originally recognized and defined by Thorndike (1920) as the "ability to understand and manage others". Mayer \&Salovey (1990) defined emotional intelligence as "the subset of social intelligence that involves the ability to monitor one's own and others feelings and emotions to discriminate among them and to use this information to guide ones thinking and actions". In generally, EI involves behavior related to the experience of emotion;specifically those which involve expressing, recognizing, understanding and managing emotions. 
In recent themes EI has surfaced as an appreciated capability for job and life performance. EI is essential in determining success in life and psychological well being and also is crucial in influencing the interaction between individuals and their work environment (Oginska -Bulik,2005). As regards the function of EI, it relates by some means to an improved adjustment or success at occupational settings and is an important factor in determining low job stress and high work satisfaction (Bar-On, Brown, Kircaldy\& Thome,2000). Goleman (1998) states EI as doubly important to technical skills and more significant than IQ for success in all jobs.

Excessive occupational stress can lead emotional and physical disorders that began to impact personal as well as professional lives. A 1992 UN (United Nations) report labeled job stress as the 20th century disease subsequently the WHO (World Health Organization) has endorsed that occupational stress had become a "Worldwide Epidemic" similarly United Nations International LaborOrganization has defined occupational stresshas Global Epidemic. Occupational stress refers to the response people may have when presented with work disability. Occupational stress refers to the response people may have when presented with work demands and pressure that are not matched to their ability to cope (Leka, Griffiths and Cox,2004).Syriacou and Sutcliffe (1978) defined occupational stress as the experience of unpleasant emotions, such as tension, anger,frustration, anxiety, and depression. The entangled association between occupational stress and emotion has also been proposed to play a role in the stress -outcomes relationship. Self management of emotions and appropriate appraisal of others emotions occupy a pivotal role in managing work stress. Especially in the teaching profession, Chan(2006), found that some components of EI, such as emotional appraisal and positive regulation of emotions, prevent emotional exhaustion that often leads to depersonalization and a low sense of personal accomplishment.

\section{Significance of the Problem}

Despite the paramount interest in emotional intelligence (EI)at workplace, negligible empirical literature is available examining the role EI might perform in occupational stress (Slaski and Cartwright,2002). Contemporary researches support the view that EI is learned and can be developed and since certain aspects of EI are pertinent of work-stress (King and Gardner, 2006) subsequently an understanding about their nature of relationship is imperative for both employers in organizations for enriching EI and thereby managing occupational stress. Most of the empirical work in organizational context has focused mainly on the relationship between EI, leadership effectiveness, job satisfaction, self efficacy and organizational commitment (e.g., Adeyemo,2007; Chan, 2004 George, 2000; Chiva and Alegre,2008); researches investigating the relationship between EI and occupational stress are less and particularly within the framework of academic institutions such studies on understanding the relationship between EI and occupational stress pertaining to educational scenario relatively seems more inadequate. Hence this research is an effort made to usage the deficiency in empirical evidence about the nature of this relationship between EI and occupational stress among Degree College Teachers. This study also investigates the role of demographic factors upon EI and occupational stress.

\section{Objectives of the Study}

1. To know the relationship between emotional intelligence and occupational stress among degree college teachers.

2. To find out the effect of socio demographicvariables on occupational stress among degree college teachers.

\section{Hypotheses of the Study}

1. There is no significant relationship between emotional intelligence and occupational stress among degree college teachers.

2. There is no significant difference the mean scores of selected socio demographic variables on occupational stress and emotional intelligence among Degree College teachers.

\section{Sample}

The sample comprised of 200 Degree College Teachers(110 males and 90 females) between the age group of 28 to 60 years (mean Age $=46.7$ years ) randomly selected from VSK University, Bellary, Karnataka, India.

\section{Methodology}

In the Present Study Investigator adopted descriptive research method under correlation and causal comparative types of research were followed. To know the independent variable on dependent variable.

\section{Tools Used}

a) Emotional Intelligence Scale: The emotional intelligence scale developed by Hyde, Pethe, and Dhar (2002). This scale consists of 34 items with 10 dimensions, namely (1) selfawareness (2) empathy (3) self -motivation (4) emotional stability (5) managing relations (6) integrity (7) self development (8)value orientation (9) commitment 
and (10) altruistic behavior. It is a 5 point scale with alternatives such as strongly agree, agree, undecided , disagree, and strongly disagree, The responses were given scores ranging from 5 for strongly agree to strongly disagree, the split -half reliability coefficient of the scale was found to be 0.88 .

b) Occupational Stress Index: The occupational stress index developed by Srivastava and Singh (1981) is widely used in Indian context.The occupational stress index consists of 46 items with five alternative responses, e.g., strongly agree, mildly agree, uncertain, disagree, and strongly disagree. Total score on this index is considered for the assessment of occupational stress. More the score on this scale indicates more stress.

c) Personal Information Schedule: The personal information schedule was designed by the investigator of the present research. This aim of this schedule is to obtain relevant socio- demographic information from the respondents. This schedule consists of 6 items such as age, gender, educational qualification, residential status, job status, and family type.

\section{Procedure}

The samples were contacted individually by us and we obtained the data through face -to face interview using structure questionnaires. The data collection was done over a period of one month. The obtained responses of were scored and statistically analyzed, Mean, standard deviation, t-test and Pearson product moment correlation were the statistical analysis done by us using the statisticalpackage for social science (SPSS) 17 version is used.

10. Result and Discussion

TABLE-1:Showing the Pearson Product Moment Correlation between Emotional Intelligence and OccupationalStress.

\begin{tabular}{|c|c|c|c|c|c|}
\hline Variables & $\underline{\mathbf{N}}$ & Mean & $\underline{\underline{\text { SD }}}$ & $\underline{\mathbf{r}}$ & $\underline{\mathbf{L S}}$ \\
\hline $\begin{array}{l}\text { Emotional } \\
\text { Intelligence Stress }\end{array}$ & $\underline{200}$ & $\underline{129.33}$ & $\underline{10.194}$ & & \\
\hline $\begin{array}{l}\text { Occupational } \\
\text { Stress } \\
\end{array}$ & $\underline{200}$ & $\underline{120.76}$ & $\underline{18.436}$ & $\underline{-0.463 * *}$ & $\underline{0.01}$ \\
\hline
\end{tabular}

Significant at 0.01 levels.

The results summarized in table 1 indicates a significant negative correlation between emotional intelligence (EI) and occupational stress ( $\mathrm{r}$ value $=-0.463<0, \mathrm{p}<0.01$ ). This outcome clearly indicates in inverse relationship between EI and occupational stress among Degree College Teachers. That is individuals with high EI seem to experience low levels of occupational stress and vice versa. This finding of the present research appear analogues to the results of prior studies by Nikolaou and Tsaousis (2002), Panda (2008) and Mohammady et.al (2009), which also point out an inverse relationship between EI and work stress. Saloveyet.al (2000) emphasized EI as the main element distinguishing people who efficiently cope with stressful situations from those who are inefficient. Ciarrochet. al (2002) found that EI has moderating effect on stress. Depression, hopelessness and suicidal tendency. Another germane elucidation about the relationship between EI and occupational stress comes from the undoing hypotheses formulated by Fredrickson which proposes that positive emotions disengage the protracted consequence of negative emotions (Fredrickson and Levenson , 1998) Many studies (e.g.Pilsuk and Parks, 1984) highlight that certain aspects of EI such as recognizing others emotions are the basis of healthy relationships, strong social network, and sound social support which subsequently acts as a buffer for the ill effect of distress. The current finding further braces the exiting empirical knowledge regarding the negative relationship between EI and occupational stress.

Table-2: Showing the Mean, SD, and t-value for Emotional Intelligence of College Teachers on Socio Demographic Variables.

\begin{tabular}{|c|c|c|c|c|c|c|}
\hline \multicolumn{2}{|l|}{ Variables } & $\underline{\mathbf{N}}$ & Mean & $\underline{\text { SD }}$ & $\underline{\text { 't'}}$ & $\underline{\mathbf{L S}}$ \\
\hline \multirow{2}{*}{ Age } & Above 40 & $\overline{\mathbf{1 3 5}}$ & $\overline{131.32}$ & $\overline{9.20}$ & \multirow{2}{*}{$\underline{2.053}$} & \multirow{2}{*}{$\underline{0.05}$} \\
\hline & Below 40 & 65 & 127.40 & $\overline{9.45}$ & & \\
\hline \multirow[b]{2}{*}{$\underline{\text { Gender }}$} & Male & $\underline{110}$ & 128.90 & $\overline{10.65}$ & \multirow[b]{2}{*}{$\underline{0.657}$} & \multirow[b]{2}{*}{$\underline{\mathbf{N S}}$} \\
\hline & $\overline{\text { Female }}$ & $\overline{90}$ & $\overline{132.50}$ & $\overline{5.91}$ & & \\
\hline \multirow{2}{*}{$\begin{array}{l}\text { Educational } \\
\text { Qualification }\end{array}$} & Post - graduate above & $\overline{110}$ & 130.50 & $\overline{8.46}$ & \multirow{2}{*}{$\underline{1.235}$} & \multirow{2}{*}{$\underline{\mathbf{N S}}$} \\
\hline & $\overline{\text { Post Graduate }}$ & $\overline{90}$ & 125.14 & $\underline{15.16}$ & & \\
\hline \multirow{2}{*}{$\underline{\text { Job Status }}$} & Professors & $\underline{125}$ & $\underline{128.07}$ & $\underline{11.45}$ & \multirow{2}{*}{$\underline{0.65}$} & \multirow{2}{*}{$\underline{\text { NS }}$} \\
\hline & Assistant Professors & $\overline{75}$ & 130.39 & $\overline{9.22}$ & & \\
\hline \multirow{2}{*}{ Family Type } & Nuclear & $\underline{\overline{143}}$ & $\overline{129.19}$ & $\overline{\overline{8.10}}$ & \multirow{2}{*}{$\underline{0.151}$} & \multirow{2}{*}{$\underline{\mathbf{N S}}$} \\
\hline & $\overline{\text { Joint }}$ & $\overline{57}$ & $\overline{129.86}$ & $\overline{16.73}$ & & \\
\hline \multirow{2}{*}{ Residence Status } & Rural & $\underline{\overline{125}}$ & $\underline{\underline{128.59}}$ & $\underline{9.37}$ & \multirow{2}{*}{$\underline{0.586}$} & \multirow{2}{*}{$\underline{\mathbf{N S}}$} \\
\hline & Urban & $\underline{75}$ & 130.82 & $\underline{12.01}$ & & \\
\hline
\end{tabular}

Significant at 0.05 levels. NS -Not significant 
TABLE -3: Showing the Mean, SD, and t-value for Occupational Stress of College Teachers Socio Demographic Variables.

\begin{tabular}{|c|c|c|c|c|c|c|}
\hline \multicolumn{2}{|l|}{ Variables } & $\underline{\underline{N}}$ & Mean & $\underline{\text { SD }}$ & 't't' & $\underline{\mathbf{L S}}$ \\
\hline \multirow{2}{*}{ Age } & Above 40 & 135 & 118.23 & 20.84 & \multirow{2}{*}{$\underline{0.951}$} & \multirow[b]{2}{*}{$\underline{\mathbf{N S}}$} \\
\hline & $\overline{\text { Below 40 }}$ & $\overline{65}$ & $\overline{127.40}$ & $\overline{9.45}$ & & \\
\hline \multirow{2}{*}{ Gender } & Male & 110 & 119.86 & 19.39 & \multirow{2}{*}{$\underline{0.746}$} & \multirow{2}{*}{$\underline{\text { NS }}$} \\
\hline & Female & $\underline{90}$ & 127.25 & 7.365 & & \\
\hline \multirow{2}{*}{$\frac{\text { Educational }}{\text { Qualification }}$} & $\frac{\text { Post }- \text { graduate }}{\text { above }}$ & $\underline{110}$ & $\underline{127.77}$ & $\underline{16.39}$ & \multirow{2}{*}{1.22} & \multirow[t]{2}{*}{$\underline{\mathrm{NS}}$} \\
\hline & Post Graduate & 90 & 113.29 & 24.72 & & \\
\hline \multirow{2}{*}{$\underline{\text { Job Status }}$} & Professors & $\underline{125}$ & 127.13 & $\overline{15.74}$ & \multirow{2}{*}{$\underline{1.88}$} & \multirow{2}{*}{$\underline{\mathrm{NS}}$} \\
\hline & Assistant Professors & 75 & 115.44 & 19.23 & & \\
\hline \multirow{2}{*}{ Family Type } & Nuclear & $\underline{143}$ & $\underline{120.12}$ & $\underline{19.30}$ & \multirow{2}{*}{$\underline{0.380}$} & \multirow{2}{*}{$\underline{\text { NS }}$} \\
\hline & Joint & 57 & 123.14 & 15.89 & & \\
\hline \multirow{2}{*}{$\underline{\text { Residence Status }}$} & Rural & 125 & 122.14 & $\overline{13.78}$ & \multirow{2}{*}{$\underline{0.601}$} & \multirow[b]{2}{*}{$\underline{\mathbf{N S}}$} \\
\hline & Urban & $\overline{75}$ & 118 & $\overline{26.008}$ & & \\
\hline
\end{tabular}

NS-Not significant

From the analysis of table 2 and 3 it is inferred that socio-demographic variables such as gender, educational qualification, residential status, income, and family type were insignificant in influencing both occupational stress and emotional intelligence. Only age was significant in influencing emotional intelligence but was not significant for occupational stress. Though studies on EI and age are remote and this part of EI research remain relatively dormant. Since variation in ability is frequently associated with age the revelation of this study that age exerts significant influence on EI has implications for further researches. Age progression may enriches life experiences leading to emotional maturity which might enables appraisal of others emotions and control one's own emotion.

\section{Conclusion}

In this study we found a negative relationship between EI and occupational stress. We also found that socio demographic variables such as gender, educational qualification, residential status, income and family type were not significant in influencing both occupational stress and emotional intelligence. However, age had a significant influence on emotional intelligence but was not on significant for occupational stress.

\section{References}

Adeyemo. D.A(2007). Emotional intelligence and the relationship between job satisfaction and organizational commitment of employee in public parastals in Oyo state. Nigeria. Pakistan Journal of Social Science, 4,324330

Bar-On, R., Brown., J.M., Kircaldy. B.D and Thome, E.P(2000). Emotional expression and implications for occupational stress; an application of the emotional quotient inventory. Personality and Individual Differences, 28, 1107-1118.

Gardner, H(1993). Multiple intelligences. New York :Basic Books.

King, $\mathrm{M}$ and Gardner, $\mathrm{D}(2006)$. Emotional intelligence and occupational stress among professional staff in New Zealand; International Journal of Organizational analysis, 14(3), 186-203.

GolemanD(1998).Working with Emotional Intelligence. New York; Bantum books.

Hyde, A, Pethe,S. and Dhar, U(2002) Emotional Intelligencescale. (EIS), Lucknow: Vedant publications.

Salovey P. Mayer. J.D(1990). Emotional intelligence.Imagination, Cognition, Personality, 9, 185-211.

Srivastava, A.K and Singh. A.P(1981). Construction and Standardization of an occupational stress index ; A pilot study. Indian Journal of Clinical Psychology, 8, 133-136.. 